\title{
VOICE OPERATED WHEEL CHAIR
}

\author{
Jayesh K. Kokate ${ }^{1}$, A. M. Agarkar ${ }^{2}$ \\ ${ }^{I}$ Student ME, ${ }^{2}$ Professor, Dept. of Electronics \& Telecommunication, SSGMCE, Shegaon, Maharashtra, India
}

\begin{abstract}
This paper presents the voice operated wheel chair for handicapped person which is controlled with the voice command from handicapped person. This chair is battery powered wheel chair with DC motors. Voice command input is taken from android mobile and converted into the text and this text is given to Microcontroller via Bluetooth module to control the operation of DC motors. Also an IR detection system is used to detect the obstacle in the path of wheel chair and to avoid the collision of wheel chair. This chair makes handicapped person independent for movement purpose.
\end{abstract}

Keywords: Voice operated, Wheel chair, WHO, Disability, Android Mobile, Bluetooth Module, IR Module, PIC 16F877, DC motors

\section{INTRODUCTION}

"World report on disability" (2011) [5] jointly presented by World Health Organization (WHO) and World Bank says that there are 70 million people are handicapped in the world. Unfortunately day by day the number of handicapped people is going on increasing due to road accidents as well as disease like paralysis. Among all the disabilities percentage of physically handicapped person is most. If a person is handicapped he is dependent on other person for his day to day work like transport, food, orientation etc. So a voice operated wheel chair is developed which will operate automatically on the commands from the handicapped user for movement purpose. As an input device an android mobile is used, this is also used to convert speech signal into text. Bluetooth module transfer signal from mobile to PIC 16F877 controller which controls the direction of wheel chair and an IR section is used to detect the obstacle in the path of wheel chair. Two DC motors are used with L298 which is a dual full bridge driver IC. The following section gives an idea about statistics on disability in India among which physical disability is having highest percentage.

\subsection{Indian Statistics on Disability}

We know that at every second the population of World as well as India is increasing very rapidly. In India 120 million people are disabled out of which $41.32 \%$ are physically disabled [6]. Unfortunately the number of physically disabled people is continuously increasing due to reasons like accidents and the disease like paralysis. The graphical representation of disability in India is represented in figure 01. The statistics given below is in percentage out of 120 million people.

Physical Disability $41.32 \%$

Visual Impairment $10.32 \%$

Hearing Impairment $8.36 \%$

Speech Disability 5.06\%
Locomotors Disability 23.04\%

Overlapping $11.54 \%$

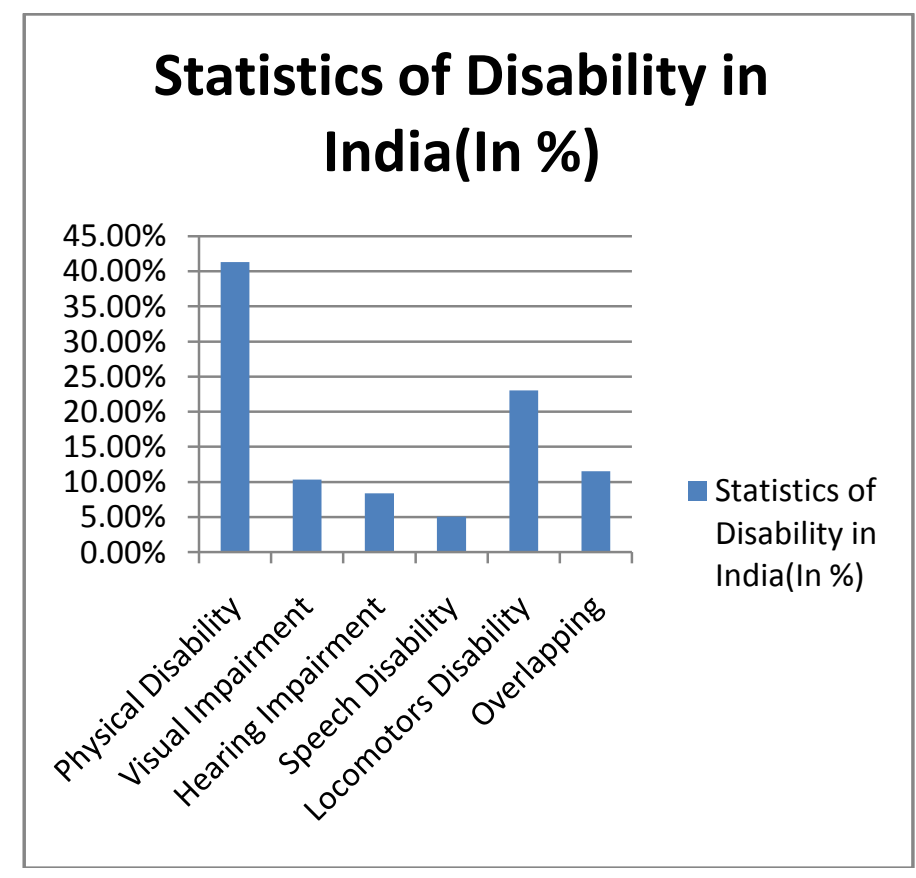

Fig 1: Statistics of Disability in India.

It is important to see the recommendations of WHO in case of disabled person as given in section 1.2.

\subsection{Recommendations by WHO}

$>$ Enable access to all mainstream policies, systems and services.

$>$ Invest in specific programmes and services for people with disabilities. 
$>$ Adopt a national disability strategy and plan of action.

$>$ Involve people with disabilities.

$>$ Improve human resource capacity.

$>$ Provide adequate funding and improve affordability.

$>$ Increase public awareness and understanding of disability.

$>$ Improve disability data collection.

$>$ Strengthen and support research on disability.

Authors are motivated due to statistical data in section 1.1 and recommendations by WHO in section 1.2 and many important points are considered as the driving force for the project undertaken.

\section{LITERATURE SURVEY}

In the paper on "Voice Operated Intelligent Wheelchair" [1], Matlab software is used for input signal processing and that signal is given to the ARM Processor LPC2138 which is used to control the movement of wheel chair by controlling the DC motors. Input to Matlab is provided with the help of headphone according to input signal, controller will decide the operations of two DC motors.

In the paper on "Voice and Touch Screen Based Direction and Speed Control of Wheel Chair for Physically Challenged Using Arduino" [2], input is provided to the Arduino which is a Microcontroller used to control the motion of wheel chair via two ways first way is with the help of voice command or second way is with the help of a Touch screen. HM 2007 is used for voice recognition purpose. A switch is used to switch between the input methods. The Arduino controls the movement of wheel chair based on the input signal received from any one of input methods. For movement of wheel chair two DC motors are used.

In another paper on "A Wheelchair Steered through Voice Commands and Assisted by a Reactive Fuzzy-Logic Controller" [3], wheel chair is controlled through the voice command and a reactive fuzzy logic controller is used and also a sensor network is used to avoid the collision of wheel chair with obstacles here reactive fuzzy logic controller is used because sometimes voice input from the user is low and that leads to wrong working of wheel chair. So a fuzzy logic controller is used for proper operation of wheel chair. With this reactive fuzzy logic controller and network of sensors the wheel chair is semi autonomous in nature.

It is described in [7], HM 2007 IC is used for the voice recognition purpose. HM 2007 generates the output signal depending on the input from the user and that signal is given to PIC 16F877 controller which is used to control the motion of wheel chair. Two DC motors are used to control the motion of wheel chair.

\section{FLOWCHART}

The flowchart is as shown below in figure 02 .

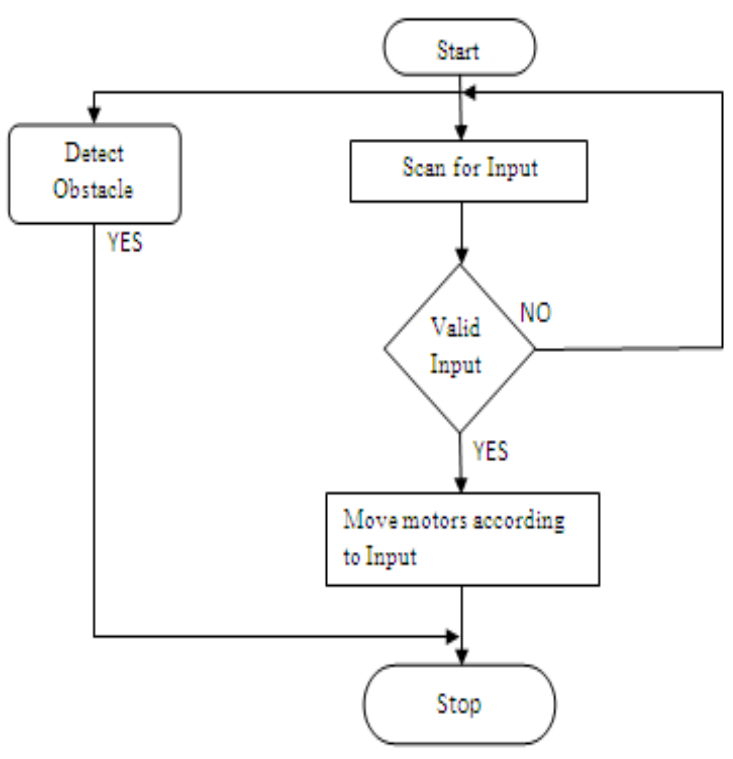

Fig 2: Basic Flowchart

\section{HARDWARE REQUIREMENTS}

AND

\section{WORKING PRINCIPLE}

\subsection{Block Diagram}

The block diagram is as shown in figure 03 .

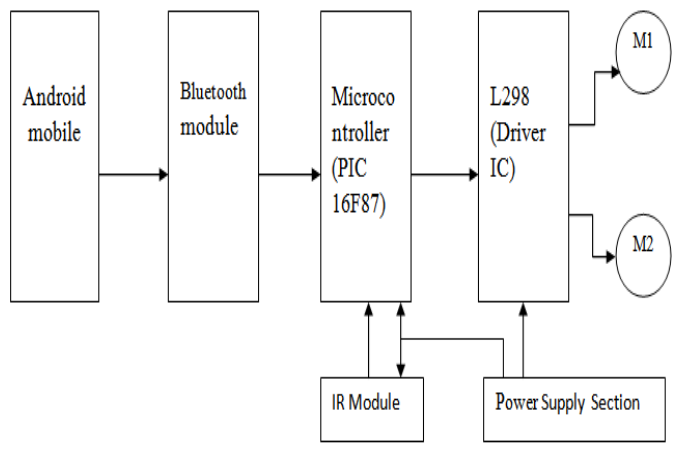

Fig 3: Block diagram.

\subsection{Working}

Here input is taken from the android mobile, speech signal is converted into the text with the help of an android application. This text is transfer to the Microcontroller PIC 16F877 which controls the movement and direction of wheel chair via a Bluetooth module wirelessly. Microcontroller PIC 16F877 decides the operation of the two DC motors depending on the text received.L298 is a dual full bridge driver IC which is used for driving purpose of DC motors. 
The wheel chair directions and movement possible are as given below.

Forward: Both motors are in forward direction.

Reverse: Both motors are in reverse direction.

Left: Left motor stopped and right motor in forward direction.

Right: Right motor stopped and left motor in forward direction.

Stop: Both motors are stopped.

\subsection{Hardware Description}

\subsubsection{An Android Mobile:}

Any an android mobile can be used. It is used as input device it receives the voice command from the handicapped user and converts this speech signal into text with the help of an android application. Transfer this text to Bluetooth module with the help of Bluetooth wirelessly.

\subsubsection{Bluetooth Module:}

Bluetooth module is used to transfer data from an android mobile to the Microcontroller PIC 16F877 wirelessly. This module enables to wireless transmit and receive serial data. This module is having 10 meters range. Operate on 5v supply. Easily interface with Microcontroller.

\subsubsection{IR Module:}

This module uses combination of IR Transmitter and IR receiver and IC 555. This is used to detect an obstacle in the path of wheel chair and if an obstacle is detected then it will send a signal to Microcontroller and wheel chair will be stop. It detects the larger obstacle in the range of $15 \mathrm{~cm}$. It operates on $36 \mathrm{KHz}$ frequency. The working diagram of IR module is as shown in figure 04 below.

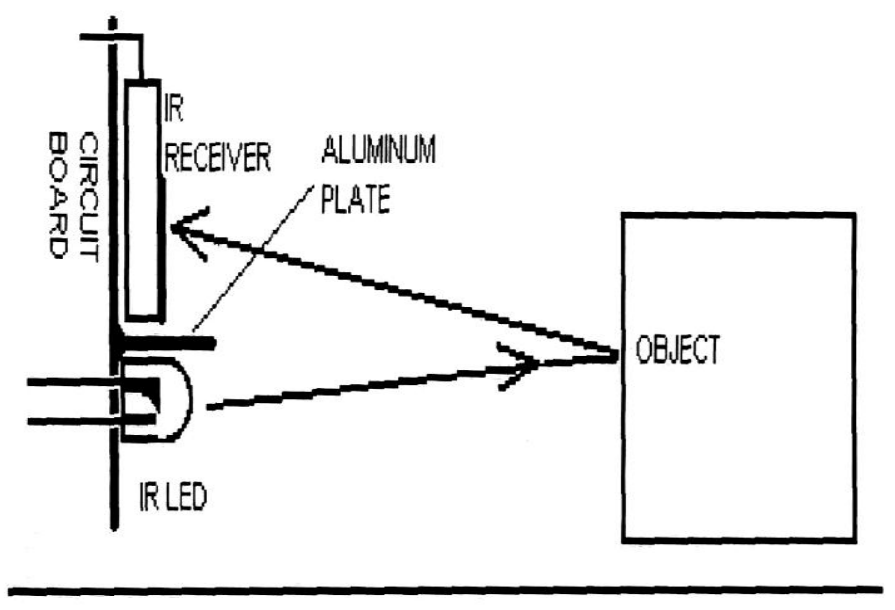

Fig 4: IR module.

\subsubsection{L298 (Driver IC):}

It's a high voltage and high current dual full bridge driver IC having 15 pin. This is used to drive the DC motors. It operates on $12 \mathrm{~V}$ power supply. It provides DC current up to $4 \mathrm{~A}$. The operating supply voltage is up to $46 \mathrm{~V}$. This is having over temperature protection and also having high noise immunity means logical ' 0 ' voltage is up to $1.5 \mathrm{~V}$.

\subsubsection{Motors:}

Two DC motors are used for the movement of the wheel chair in Forward, Reverse, Left, and Right Direction. These motors are controlled from the Microcontroller. L298 is a dual bridge driver IC is used for driving the DC motors.

\subsubsection{Power Supply Section}

This section is consisting of a rechargeable battery. This section deals with the power requirements of the wheel chair for DC motors, Microcontroller and other Section. Battery is used to provide the power supply to L298 driver IC (12V supply) which drives the DC motors, Microcontroller and IR section operates on $5 \mathrm{~V}$ supply which is provided with the help of LM7805 which is a $5 \mathrm{~V}$ regulator IC by converting $12 \mathrm{~V}$ into $5 \mathrm{~V}$.

\subsubsection{Microcontroller PIC 16F877:}

This is a 40 pin programmable interrupt microcontroller. It is a high performance RISC CPU. This is used for controlling the movement and direction of wheel chair by controlling the two DC motors. The details of microcontroller are given in following section 4 .

\section{SELECTION OF THE MICROCONTROLLER}

This is a 40 pin programmable interrupt microcontroller. It is a high performance RISC CPU. This is used for controlling the movement and direction of wheel chair by controlling the two DC motors. This microcontroller controls the operation of DC motors according to data received from the Bluetooth module. It controls the movement of wheel chair like Forward, Reverse, Left, Right, and Stop. Also an IR module is connected to Microcontroller if a obstacle is detected in the path of a wheel chair the microcontroller will stop the wheel chair. It operates on $5 \mathrm{v}$ supply. Only having 35 instructions set. It operates on $20 \mathrm{MHz}$ clock input. The comparison of PIC and other Atmega processor is given below and the reason of choosing the PIC 16F877 is low operating voltage, Low Instruction set, High operating speed etc. The comparison of PIC16F877 and Atmega 16 and Atmega 32 is as given below in table 01 from which it is clear that why we choose the PIC 16F877 Microcontroller. 
Comparison of Controllers [8], [9], [10]

Table 1: Comparison of Microcontrollers.

\begin{tabular}{|l|l|l|l|}
\hline Parameter & $\begin{array}{l}\text { PIC } \\
\text { 16F877 }\end{array}$ & Atmega16 & Atmega32 \\
\hline Instructions & 32 & 131 & 131 \\
\hline $\begin{array}{l}\text { Operating } \\
\text { Speed }\end{array}$ & $\begin{array}{l}\mathrm{DC}-20 \\
\mathrm{MHz}\end{array}$ & $16 \mathrm{MHz}$ & $16 \mathrm{MHz}$ \\
\hline $\begin{array}{l}\text { Flash } \\
\text { Program } \\
\text { Memory }\end{array}$ & $\begin{array}{l}\text { Up to } 8 \mathrm{~K} \text { x } \\
14 \text { words }\end{array}$ & $\begin{array}{l}16 \mathrm{~Kb} \text { in } \\
\text { system }\end{array}$ & $\begin{array}{l}32 \mathrm{~Kb} \text { in } \\
\text { system }\end{array}$ \\
\hline $\begin{array}{l}\text { Data } \\
\text { Memory }\end{array}$ & $\begin{array}{l}\text { Up to } 368 \\
\text { x } 8 \text { bytes }\end{array}$ & 1 Kbyte & 2 Kbytes \\
\hline EEPROM & $\begin{array}{l}\text { Up to } 256 \\
\text { x } 8 \text { bytes }\end{array}$ & 512 Bytes & $1024 \mathrm{Bytes}$ \\
\hline $\begin{array}{l}\text { Timer/ } \\
\text { Counter }\end{array}$ & $\begin{array}{l}3(2-8 \text { bit, } \\
1-16 \text { bit })\end{array}$ & $\begin{array}{l}3(2-8 \text { bit, } 1- \\
16 \text { bit })\end{array}$ & $\begin{array}{l}3(2-8 \text { bit, } \\
1-16 \text { bit })\end{array}$ \\
\hline USART & Yes & Yes & Yes \\
\hline $\begin{array}{l}\text { Operating } \\
\text { Voltage }\end{array}$ & $\begin{array}{l}2.0 \mathrm{~V} \text { to } \\
5.5 \mathrm{~V}\end{array}$ & $4.5 \mathrm{~V}-5.5 \mathrm{~V}$ & $\begin{array}{l}4.5 \mathrm{~V}- \\
5.5 \mathrm{~V}\end{array}$ \\
\hline $\begin{array}{l}\text { A/D } \\
\text { converter }\end{array}$ & $\begin{array}{l}10 \text { bit } 8 \\
\text { channel }\end{array}$ & $\begin{array}{l}10 \text { bit } 8 \\
\text { channel }\end{array}$ & $\begin{array}{l}10 \text { bit } 8 \\
\text { channel }\end{array}$ \\
\hline Cost & $185 /-$ & $180 /-$ & $255 /-$ \\
\hline
\end{tabular}

\section{ADVANTAGES:}

$>$ A handicapped person even with Legs and Hand can use this and become Independent.

$>$ Very rapidly changing input can be easily recognized due to Android mobile.

$>$ Suitable for practical application as compare to HM 2007.

$>$ Requires less wiring because of Bluetooth section.

$>$ Less Hardware require i.e. compact.

$>$ Economical.

$>$ Reduce manpower.

$>$ User friendly.

\section{CONCLUSIONS}

Android mobile is used instead of Voice recognition ICs like HM2007 the efficiency to detect voice command and control the wheel chair is significantly increased. This voice operated wheel chair will assist the handicapped persons to make them self dependent for the purpose of movement for which these people are dependent on other most of the times. A person with disabled with legs and arms can use this wheel chair efficiently if he is able to speak.

\section{FUTURE SCOPE}

Further advancement in this wheel chair are possible by decreasing the power requirements of the wheel chair or finding a way to automatically charge the battery with the help of motion of the wheel chair or solar panel .

\section{ACKNOWLEDGEMENTS}

I am thankful to Dr. S. B. Somani, Principal and Prof. G. S. Gawande, HOD (EXTC) of Shri Sant Gajanan Maharaj College of Engineering, Shegaon for providing lab facilities. I am highly indebted to Dr. A. M. Agarkar and Prof. R. S. Dhekekar for their valuable Guidance and support in the tenure of the project.

\section{REFERENCES}

[1] "Voice Operated Intelligent Wheelchair" by Ms. S. D. Suryawanshi , Mr. J. S. Chitode, Ms. S. S. Pethakar, “ International Journal of Advanced Research in Computer Science and Software Engineering" Volume 3, Issue 5, May 2013.

[2] "Voice and Touch Screen Based Direction and Speed Control of Wheel Chair for Physically Challenged Using Arduino" by M.Prathyusha, K. S. Roy, Mahaboob Ali Shaik, " International Journal of Engineering Trends and Technology (IJETT)" , Volume4Issue4, April 2013.

[3] "A Wheelchair Steered through Voice Commands and Assisted by a Reactive Fuzzy-Logic Controller" by Gabriel Pires and Urbano Nunes "Journal of Intelligent and Robotic Systems" 34: 301-314, 2002.

[4] "Smart Wheelchairs: A literature Survey", by Richard Simpson "Journal of Rehabilitation Research \& Development", Volume 42, Number 4, Pages 423-436 July/August 2005.

[5] http://www.who.int/mediacentre/news/notes/2013/disa bility_and_development_20130920/en

[6] http://www.indiability.org/resources/disability-in-india

[7] www.techtriks.wordpress.com

[8] http://www.electroschematics.com/wpcontent/uploads/2013/01/PIC16F877A-Datasheet.pdf

[9] http://www.atmel.in/Images/doc2466.pdf

[10] http://www.atmel.in/Images/doc2503.pdf

\section{BIOGRAPHIES}

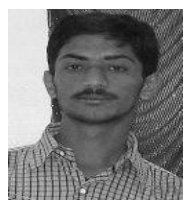

Jayesh K. Kokate, Student of ME (Digital Electronics) of Shri Sant Gajanan Maharaj College of Engineering, Shegaon. Done BE and Diploma in Electronics \& Telecommunication.

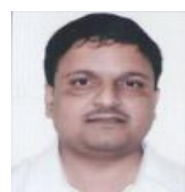

Dr. A. M. Agarkar is associated with Shri Sant Gajanan Maharaj College of Engineering, Shegaon since 1989 and currently working as a professor of Electronics \& Telecommunication dept. His areas of interest include ANN, Intelligent Systems, Embedded \& VLSI (SOC) systems and Parallel computing. 